\title{
Promoting post-stroke recovery through focal or whole body vibration: criticisms and prospects from a narrative review
}

\author{
Claudia Celletti ${ }^{1}$ (D) Antonio Suppa ${ }^{2,3} \cdot$ Edoardo Bianchini $^{2} \cdot$ Sheli Lakin $^{2} \cdot$ Massimiliano Toscano $^{2}$. \\ Giuseppe La Torre $^{4} \cdot$ Vittorio Di Piero ${ }^{2} \cdot$ Filippo Camerota $^{1}$
}

Received: 25 March 2019 / Accepted: 13 August 2019

(C) Fondazione Società Italiana di Neurologia 2019

\begin{abstract}
Objective Several focal muscle vibration (fMV) and whole body vibration (WBV) protocols have been designed to promote brain reorganization processes in patients with stroke. However, whether fMV and WBV should be considered helpful tools to promote post-stroke recovery remains still largely unclear.

Methods We here achieve a comprehensive review of the application of $\mathrm{AMV}$ and WBV to promote brain reorganization processes in patients with stroke. By first discussing the putative physiological basis of fMV and WBV and then examining previous observations achieved in recent randomized controlled trials (RCT) in patients with stroke, we critically discuss possible strength and limitations of the currently available data.

Results We provide the first systematic assessment of fMV studies demonstrating some improvement in upper and lower limb functions, in patients with chronic stroke. We also confirm and expand previous considerations about the rather limited rationale for the application of current WBV protocols in patients with chronic stroke.

Conclusion Based on available information, we propose new recommendations for optimal stimulation parameters and strategies for recruitment of specific stroke populations that would more likely benefit from future fMV or WBV application, in terms of speed and amount of post-stroke functional recovery.
\end{abstract}

Keywords Chronic stroke $\cdot$ Focal muscle vibration $\cdot$ Whole body vibration $\cdot$ Neurorehabilitation $\cdot$ Post-stroke recovery

\section{Introduction}

Stroke is the second leading cause of death after ischemic heart disease and the third leading cause of disabilityadjusted life years (DALY) worldwide [1]. Despite the significant decline of stroke mortality rates due to the introduction of new acute stroke therapies and innovative prevention

Claudia Celletti and Antonio Suppa contributed equally to this work.

Claudia Celletti

clacelletti@gmail.com

1 Physical Medicine and Rehabilitation Division, Umberto I University Hospital of Rome, Rome, Italy

2 Department of Human Neurosciences, Sapienza University of Rome, Rome, Italy

3 IRCCS Neuromed Institute, Pozzilli, IS, Italy

4 Department of Public Health and Infectious Diseases, Sapienza University of Rome, Rome, Italy strategies, the global burden of stroke has progressively increased [2]. Stroke prevalence in 2013 has almost doubled that in 1990, and the absolute number of people affected by stroke has substantially increased worldwide over the same time period, suggesting that global stroke burden continues to increase [3]. A current relevant issue concerns the design of new pharmacological and non-pharmacological strategies to promote post-stroke recovery [4-6]. Among nonpharmacological techniques possibly helpful to promote post-stroke functional recovery, increasing attention has recently been paid to protocols based on muscle vibration.

Muscle vibration was first used in 1892 when Jean-Martin Charcot, who was the most celebrated and powerful clinical neurologist of the nineteenth century, delivered a lecture on the topic of vibratory therapy in neurologic disorders: "Vibration therapeutics: Application of rapid and continuous vibrations to the treatment of certain nervous system disorders" [7]. In his lecture, Charcot summarized the historical background of vibration therapy and then focused on his own clinical experience in patients with Parkinson's disease (PD). 
Charcot died 1 year later, and although Gilles de la Tourette continued to study vibration therapy, Charcot's observations were largely forgotten [8]. About a century later, Hagbarth and Eklund (1968) studied the motor effects of fMV in patients with various types of central motor disorders, in particular, those associated with spasticity and rigidity [9]. In spastic patients, Hagbarth and Eklund observed that vibration potentiated or reduced voluntary power (and range of movement) depending upon whether the subject tried to contract the vibrated muscle or its antagonist [9]. Later, Bishop studied the neurophysiologic characteristics of the vibratory stimulation and possible associated clinical applications and found a beneficial effect induced by muscle vibration in spasticity disorders (i.e., reduced the strength of spasticity and potentiated weak voluntary movement) [10]. More recently, a growing number of researchers have tested various muscle vibration protocols including focal muscle vibration (fMV) and whole body vibration (WBV) aimed to elicit active modulation of sensory afferent inputs to the central nervous system [11]. Converging evidence from experimental studies raises the hypothesis that $\mathrm{AMV}$ and WBV might induce brain reorganization sensorimotor processes in healthy humans [12-20]. Several researchers have also investigated the possible beneficial effect of various $\mathrm{PMV}$ and WBV protocols in patients with stroke in order to promote functional recovery through brain reorganization sensorimotor processes. However, whether fMV or WBV protocols can be considered new strategies possibly helpful for promoting poststroke recovery remains largely unclear.

Here, a workgroup of researchers expert in the field has critically reviewed and discussed 10 years of randomized controlled studies (RCT) investigating the effect of fMV and WBV protocols, in patients with stroke. We focused our attention on the fMV and WBV techniques because these vibration protocols share putative physiological mechanisms possibly able to promote beneficial brain reorganization sensorimotor processes, in patients with stroke. The effect of WBV in patients with chronic stroke has been discussed only in a single previous review [21] thus covering only in part the topic. So far, none have reviewed systematically WBV and fMV studies in patients with chronic stroke in order to clarify the real impact of these vibration protocols on post-stroke motor recovery. Given the significant amount of recent research in the field and the heterogeneity of previous methodologies used and findings reported, the need for a comprehensive and updated review is relevant. We have first summarized the technical aspects and physiological basis of fMV and WBV and then critically re-examined the main methodological aspects and findings achieved in the previous RCT using $\mathrm{PMV}$ and $\mathrm{WBV}$ in patients with stroke.

\section{Literature research strategy and criteria}

The literature search was performed by means of the following databases: MEDLINE, Scopus PubMed, Web of Science,
EMBASE and the Cochrane Library. Literature criteria included the following terms: "stroke" OR "chronic stroke" AND "vibration," "stroke" OR "chronic stroke" AND "training," "stroke" OR "chronic stroke" AND "rehabilitation," "poststroke recovery" AND "vibration." Studies considered for eligibility were only RCTs published from January 2007 to July 2018 implying fMV and WBV for the treatment of patients with chronic stroke. The reference lists of retrieved articles were also manually searched for additional studies. Furthermore, reviews, reports, and unpublished articles were not considered in this study (Fig. 1). Owing to the heterogeneity in methodology used and outcome measures reported in previous studies, we organized a narrative review according to the International Narrative Systematic assessment, INSA tool [22].

\section{Section 1}

\section{Focal muscle vibration}

Vibration is a mechanical oscillation, i.e., a periodic alternation of force, acceleration over time. During vibration, energy is transferred from an actuator (i.e., the vibration device) to a resonator (i.e., the human body, or parts of it). fMV is commonly achieved using a mechanical stimulation placed over the target muscle using a transducer connected to a control unit; the device and the control unit are able to generate a vibratory stimulus characterized by specific parameters (Fig. 2). The two main parameters to be selected for fMV include amplitude and frequency of vibration. The extent of the oscillatory movement (peak-to-peak displacement in $\mathrm{mm}$ ) determines the amplitude of $\mathrm{fMV}$, while the repetition rate of the oscillation cycles denotes the frequency of fMV. According to the specific parameters used (e.g., amplitude and frequency) and site of application, fMV can co-activate a mixture of cutaneous mechanoreceptors such as Pacinian and Meissner's corpuscles (rapidly adapting receptors) and Ruffini corpuscle and Merkel's disk [23-25]. In addition, Golgi tendon organs are also responsive to $\mathrm{PMV}$ even though this effect likely occurs during muscle contraction, reflecting the threshold for Ib afferents activation [26-28]. However, when fMV is applied over the muscle belly or its tendon, muscle spindle primary endings (Ia fibers) are thought to be the most responsive receptors to fMV [29-31]). Each cycle of the vibratory stimulus is thought to stretch the muscle and selectively excite the primary endings of the muscle spindles causing them to fire once for each cycle of vibration [32]. Most authors seem to agree that the optimum amplitude of the vibratory stimulus is less than $0.5 \mathrm{~mm}$ because a greater value tends to lead to an overflow of the stimulus into the surrounding muscles and bone [33]. Hence, fMV given at $0.2-0.5 \mathrm{~mm}$ amplitude over a relaxed muscle is a powerful and selective stimulus of activity in Ia afferents by entraining 
Fig. 1 Literature search and study selection

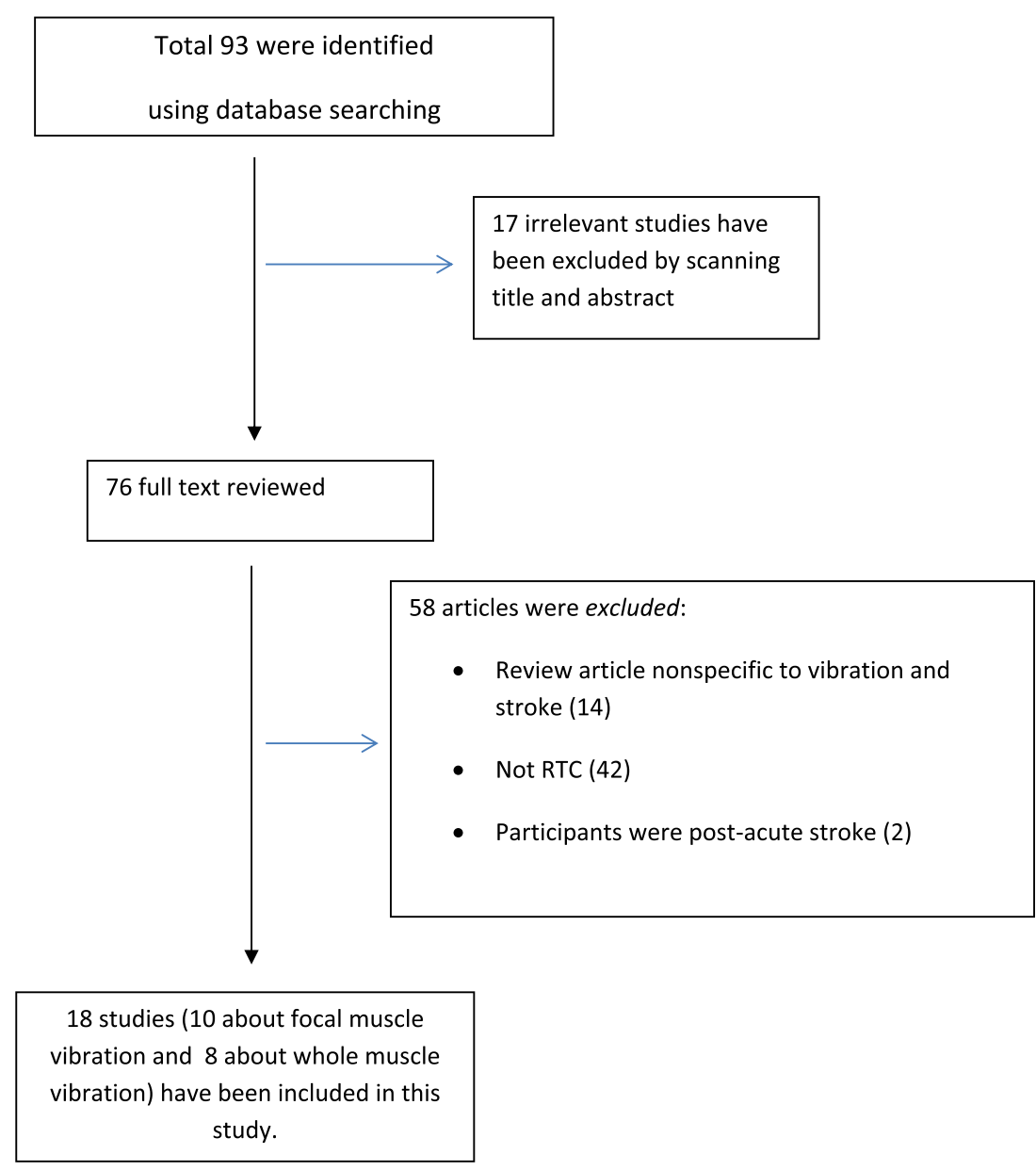

the discharge rate of primary muscle spindle endings [25, 30, 34]. FMV at amplitudes lower than $0.5 \mathrm{~mm}$ is commonly used also to avoid the Tonic vibration reflex (TVR) first described by Eklund and Hagbarth $[35,36]$. In early physiological studies in healthy subjects, Bishop observed that increases in the amplitude of vibration increases the strength of the TVR [10] which has been described as a variant of the classic myotatic reflex in response to a vibratory stimulus of low amplitude (< $3 \mathrm{~mm}$ ) at a frequency of about of $100 \mathrm{~Hz}$ [37]. During fMV, vibration applied at amplitudes $<0.5 \mathrm{~mm}$ is currently used to avoid the TVR which may prevent the voluntary tuning of muscle activation, owing to the involuntary muscle contraction. Concerning the frequency of fMV, it is known that the Ia afferent firing rate is entrained linearly with vibration frequencies up to $70-80 \mathrm{~Hz}$, followed by a subharmonic increase at higher frequencies, with sharp falls often observed at frequencies between 150 and $200 \mathrm{~Hz}$ [25, 30]. Majority of studies seem to indicate that an increase in the frequency of the vibratory stimulus is accompanied by an increase in the strength of the TVR [29, 38, 39]. Accordingly, most of the authors have used a frequency around $100 \mathrm{~Hz}$ and found this to be satisfactory for most applications [34, 40]. During fMV applications, sometimes subjects kept a steady contraction of the target muscle at $5 \%$ of the maximal force, under visual EMG feedback. Voluntary contraction is used because it has been shown that voluntary muscle activity increases response to $\mathrm{fMV}$, most likely through fusimotor co-activation and subsequent increase in spindle discharge [26].

\section{FMV in chronic stroke}

Several studies have investigated the clinical application of fMV in patients with chronic stroke in order to promote post-stroke recovery [41]. The four basic indications for focal vibration in neurorehabilitation, regardless of the neurological pathology in question, are (1) to reduce spasticity, (2) to facilitate muscle contraction of functional activity, (3) to stimulate the proprioceptive system to obtain an efficient motor control in functional activities, and (4) to provide a proprioceptive training and restore sensorimotor organization in movement disorders [41].

The demographic data and clinical features of participants are shown in detail in Table 1. A detailed description of purposes, technical aspects of $\mathrm{fMV}$, outcome measures, the timing of follow-up, and finally main results achieved by each of the studies here reviewed are shown in Table 2. The mean age of the patients examined is similar among studies. With 


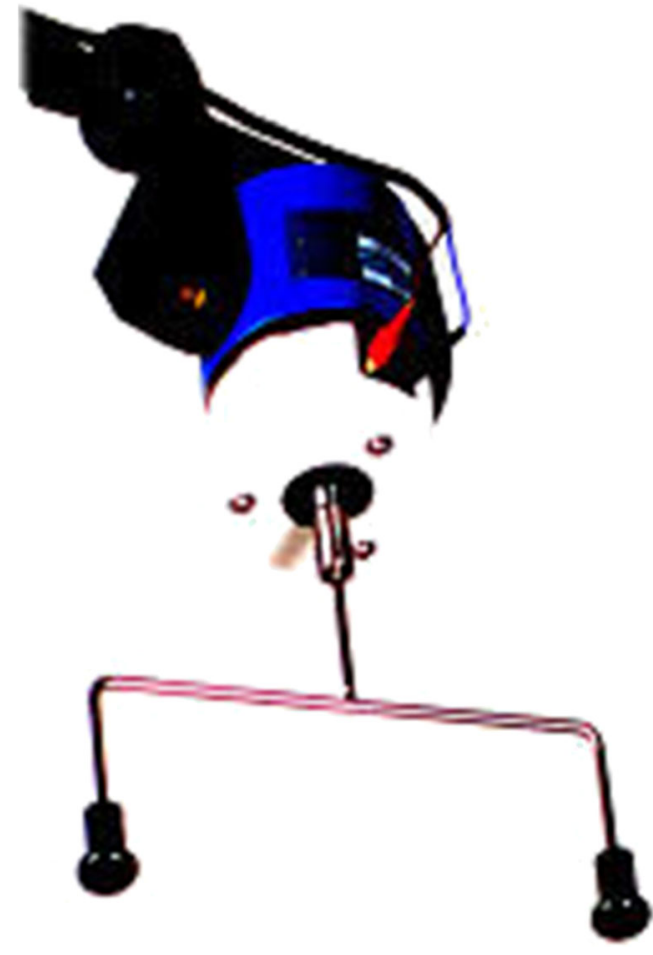

Fig. 2 A representative instrument for the application of focal muscle vibration

the exception of the study of Marconi et al. [15] and Conrad et al. [43], in the remaining studies, the male/female ratio is slightly unbalanced in favor of males [42, 44-50]. The time interval between stroke onset and fMV application varied significantly among studies since the four studies enrolled patients at a 4-6-month period from the stroke [42, 45-47], whereas the remaining studies applied fMV at least 12 months following stroke. Only four studies have provided information concerning the description of type (ischemic or hemorrhagic stroke), localization (cortical or subcortical, affected hemisphere), and extension of stroke [44, 46, 47, 50]. Only two studies reported stroke localization in detail (lesions detected by $\mathrm{CT}$ or MRI were classified as cortical or subcortical, and divided into frontal, fronto-parietal, parietal, fronto-parietaltemporal, or parietal-temporal) $[15,48]$. Although the side of the affected hemisphere (left or right) was generally balanced among studies, two studies included patients with predominant left stroke [47, 48], whereas a third study did not report the affected body side [49].

Most of the studies applied fMV over the upper limb muscles with the exception of two studies $[42,46]$ applying fMV over lower limb muscles. In the upper limb studies, fMV was delivered over different target muscles ranging from a single target muscle $[43,48]$ to three muscles treated simultaneously by means of a double application of the device such as BB and FR in Marconi et al. [25] and Tavernese et al. [47], and PP and BB in Caliandro et al. [44] and Celletti et al. [50] and then, the third muscle alone. Concerning the specific target muscles, several studies applied fMV over the wrist flexors muscles alone [15, 43-45, 47, 48], or in combination with synergic muscles such as the biceps brachialis $[15,47]$ or biceps

Table 1 Demographic data and clinical features of patients with chronic stroke in studies applying focal muscle vibration (fMV)

\begin{tabular}{|c|c|c|c|c|c|c|c|}
\hline Study & Group & $N$ & Gender $(\mathrm{M} / \mathrm{F})$ & Age (years) & Duration of disease & Side (L/R) & Type $(\mathrm{I} / \mathrm{H})$ \\
\hline \multirow[t]{2}{*}{ Paoloni et al. [42] } & EG & 22 & $19 / 3$ & $59.5(13.3)$ & $1.85(0.59)$ year & $11 / 11$ & N/A \\
\hline & CG & 22 & $20 / 2$ & $62.6(9.5)$ & $1.86(0.61)$ year & $10 / 12$ & N/A \\
\hline \multirow[t]{2}{*}{ Conrad et al. [43] } & EG & 10 & $4 / 6$ & $55.5 \pm 5.35$ & $8.8 \pm 6.87$ year & $7 / 3$ & $\mathrm{~N} / \mathrm{A}$ \\
\hline & CG & 5 & $2 / 3$ & $56.2 \pm 4.2$ & N/A & $2 / 3$ & N/A \\
\hline \multirow[t]{2}{*}{ Marconi et al. [15] } & EG & 15 & $9 / 6$ & $63.6 \pm 7.6$ & $39.9 \pm 28.8$ month & $6 / 9$ & N/A \\
\hline & $\mathrm{CG}$ & 15 & $8 / 7$ & $66.3 \pm 11.0$ & $40.6 \pm 25.1$ month & $7 / 8$ & N/A \\
\hline \multirow[t]{2}{*}{ Caliandro et al. [44] } & EG & 28 & $20 / 8$ & $57.42 \pm 12.79$ & $100.71 \pm 82.76$ month & $14 / 14$ & $18 / 10$ \\
\hline & $\mathrm{CG}$ & 21 & $14 / 7$ & $61.85 \pm 15.74$ & $96.4 \pm 66.84$ month & $12 / 9$ & $15 / 7$ \\
\hline \multirow[t]{3}{*}{ Noma et al. [45] } & EG & 12 & $8 / 4$ & $57.5(38-83)$ & $21.5(8-156)$ week & $7 / 5$ & N/A \\
\hline & CG (rest) & 12 & $8 / 4$ & $61(27-83)$ & $16(7-139)$ week & $4 / 8$ & $\mathrm{~N} / \mathrm{A}$ \\
\hline & CG (stretch) & 12 & $9 / 3$ & $61.5(41-83)$ & 16.5 (8-291) week & $5 / 7$ & N/A \\
\hline \multirow[t]{2}{*}{ Lee et al. [46] } & EG & 16 & $13 / 3$ & $53.31 \pm 8.37$ & $56.94 \pm 25.73$ month & $8 / 8$ & $10 / 6$ \\
\hline & CG & 15 & $11 / 4$ & $55.73 \pm 8.27$ & $49.93 \pm 29.97$ month & $7 / 8$ & $9 / 6$ \\
\hline \multirow[t]{2}{*}{ Tavernese et al. [47] } & EG & 24 & $21 / 3$ & $58.9 \pm 14.7$ & $19.1 \pm 18.9$ month & $16 / 8$ & $24 / 0$ \\
\hline & $\mathrm{CG}$ & 20 & $18 / 2$ & $58.3 \pm 12.4$ & $25.9 \pm 21.8$ month & $14 / 6$ & $20 / 0$ \\
\hline \multirow[t]{2}{*}{ Casale [48] } & EG & 15 & $9 / 6$ & $65.13 \pm 5.84$ & N/A & $13 / 2$ & $\mathrm{~N} / \mathrm{A}$ \\
\hline & $\mathrm{CG}$ & 15 & $9 / 6$ & $64.2 \pm 5.05$ & N/A & $14 / 1$ & N/A \\
\hline \multirow{2}{*}{ Costantino et al. [49] } & EG & 17 & $11 / 6$ & $62.59 \pm 15.39$ & N/A & N/A & N/A \\
\hline & CG & 15 & $10 / 5$ & $60.47 \pm 16.09$ & N/A & N/A & N/A \\
\hline \multirow[t]{3}{*}{ Celletti et al. [50] } & $\mathrm{EG}+\mathrm{RMP}$ & 6 & $4 / 2$ & $43(31-68)$ & $6(2-33)$ year & $3 / 3$ & $3 / 3$ \\
\hline & $\mathrm{EG}+\mathrm{CP}$ & 6 & $4 / 2$ & $43(30-57)$ & $2.5(2-4)$ year & $4 / 2$ & $2 / 4$ \\
\hline & $\mathrm{CG}$ & 6 & $4 / 2$ & $62.5(46-69)$ & $5.5(2-7)$ year & $2 / 4$ & $4 / 2$ \\
\hline
\end{tabular}




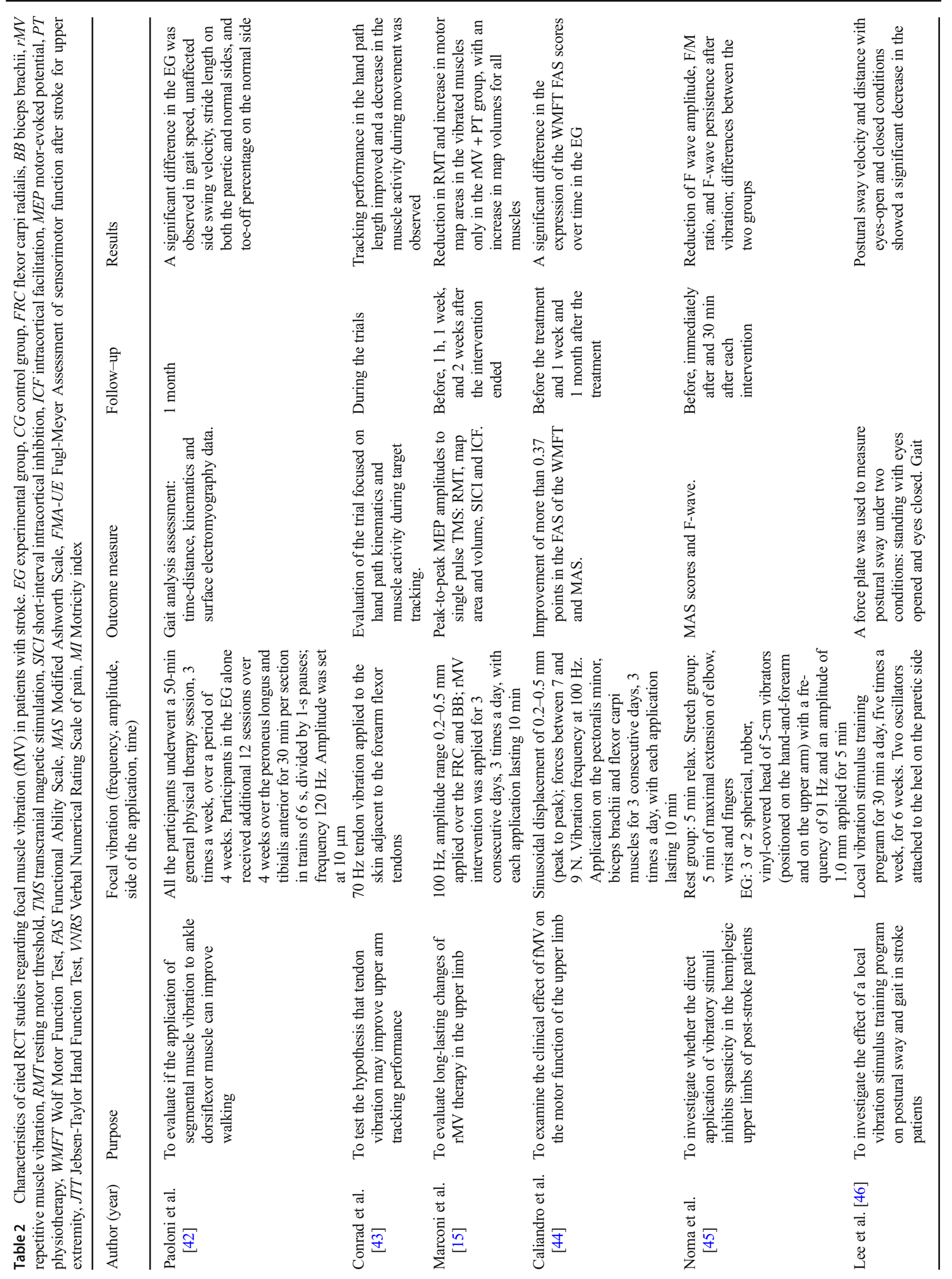




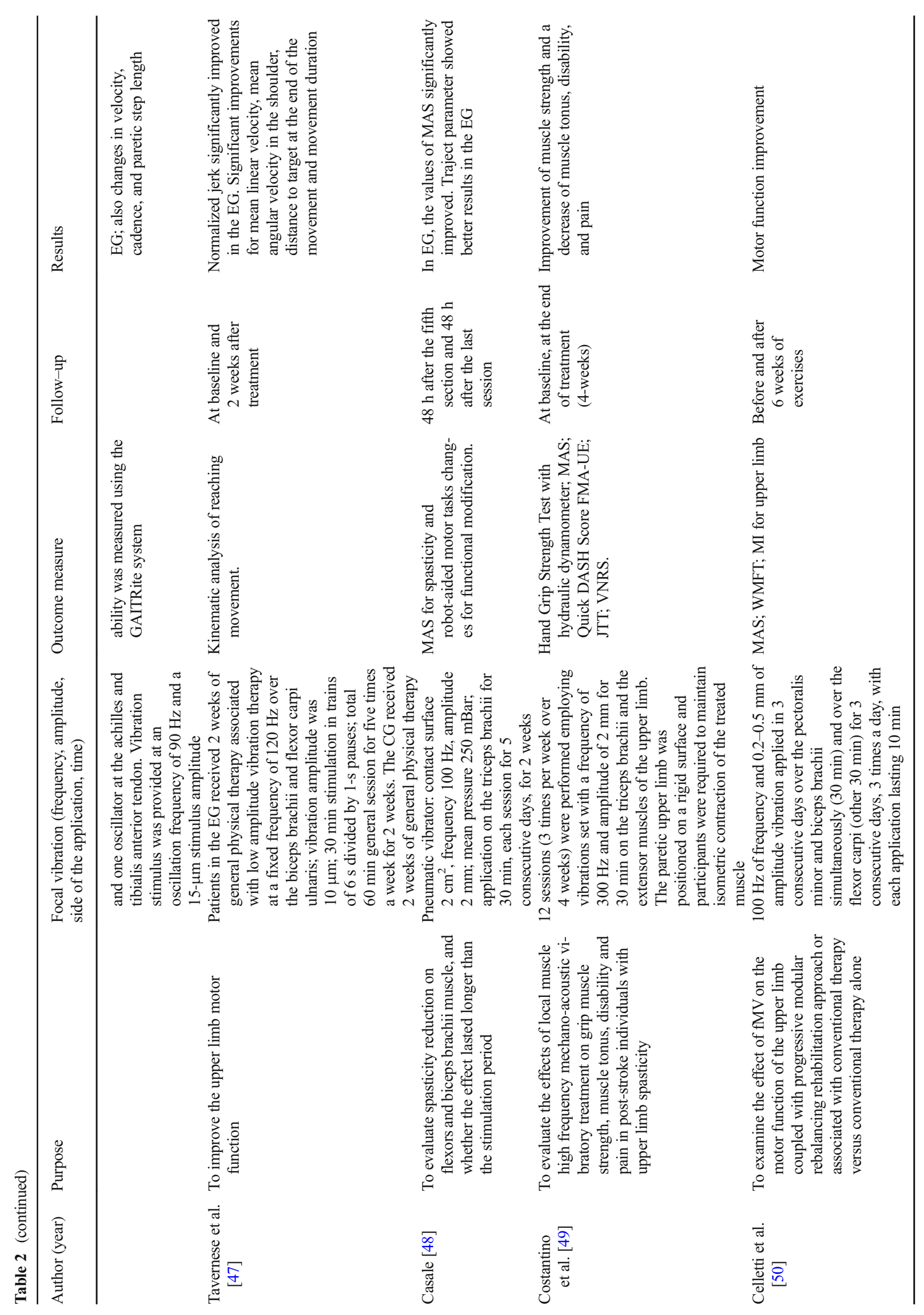


brachialis coupled with the pectoralis minor $[44,50]$ or finally in the hand [45]. By contrast, other studies applied fMV over extensor muscles [42, 46, 49] in order to improve flexor muscles spasticity. Again, several studies delivered fMV over a single muscle such as the triceps brachii alone [48] or in association with the Estensoris carpi radialis [49]. Studies applying fMV over lower limb muscles implied vibration of the peroneus longus and tibialis anterior [42] or at the Achilles and tibialis anterior tendon [46]. Concerning the simultaneous contraction of the treated muscles, only three studies adopted this paradigm $[15,44,50]$.

Concerning fMV parameters, vibration amplitude varied significantly among studies ranging from $10 \mu \mathrm{m}[42,47]$, $15 \mu \mathrm{m}[46], 0.2-0.5 \mathrm{~mm}[15,44]$ to $2 \mathrm{~mm}[48,49]$. A single study did not clarify the amplitude of fMV [43]. The frequency used in the studies varied from 70 to $120 \mathrm{~Hz}$ except for Costantino [49] who used a frequency of $300 \mathrm{~Hz}$. The duration of $\mathrm{fMV}$ and the number of sessions also varied among studies, ranging from a single session $[43,45]$, to three consecutive days $[15,44,50]$ or even more (about 10-12 sessions in four studies) [42, 47-49]. Finally, a single study applied fMV repeatedly for 30 times [46].

Outcome measures varied among studies, ranging from clinical evaluation made by standardized clinical scales (spasticity) to experimental environments including behavioral measurement (kinematics and gait analysis), and finally neurophysiological measures including TMS and EMG. For the upper limb, evaluations were done by analyzing reaching movements. Tavernese et al. [47] evaluated the reaching movement variation before and after fMV, while Conrad et al. [43] evaluated the hand kinematics and muscle activity during target tracking not only before and after but also during vibration. Interestingly, Marconi et al. [15] evaluated vibration effects on cortical activity using TMS. For the lower limbs, the evaluation was done on gait parameters by using a gait analysis system [42] or in association with postural and balance measures [46]. All the other studies used a clinical outcome scale in order to evaluate spasticity $[44,45,48,50]$ or hand function [44, 48-50]. Noma et al. [45] used also $\mathrm{F}$ wave parameters to evaluate spasticity. A detailed description of the main results achieved by the fMV studies reviewed is shown in Table 2.

\section{Section 2}

\section{Whole body vibration}

WBV consists of a mechanical stimulus characterized by an oscillatory movement portrayed by specific parameters such as amplitude, frequency, and finally magnitude (acceleration) of oscillations. The magnitude of oscillations is commonly reported in $g$ or $g$-force values according to the following formula: $g=[D(2 \pi \times \mathrm{Hz}) 2] / 9.81$, where $D$ indicates the displacement of the platform (amplitude of WBV) [51, 52]. WBV is practically delivered by means of a vibrating platform where participants stand in a static position or move dynamically (Fig. 3). Two different types of WBV have been reported. The first type of WBV is achieved by means of a platform that vibrates in a predominantly vertical direction with 4-mm peak-to-peak amplitude. Differently, the second type of WBV is given through a platform able to rotate around an anteroposterior horizontal axis. Contrarily from the first type of WBV, the second type of WBV implies an asynchronous application of vibration to the left and right foot and thus an asymmetric perturbation of the legs [53]. Given that, as for $\mathrm{fMV}$, also WBV is thought to entrain muscle spindles and subsequently, alpha-motoneuron firing rate possibly leading to the TVR [51], several authors have investigated the possible beneficial effects of WBV to boost muscle strengthening and improving proprioception control in healthy athletes [51]. The frequencies used for exercise range from 15 to $44 \mathrm{~Hz}$ and displacements range from 3 to $10 \mathrm{~mm}$. Acceleration values range from 0.3 to $15 \mathrm{~g}$ (where $g$ is the Earth's gravitational field or $9.81 \mathrm{~m} / \mathrm{s}-2$ ) $[51,52]$. Thus, vibration provides a perturbation of the gravitational field during the time course of the intervention $[51,52]$.

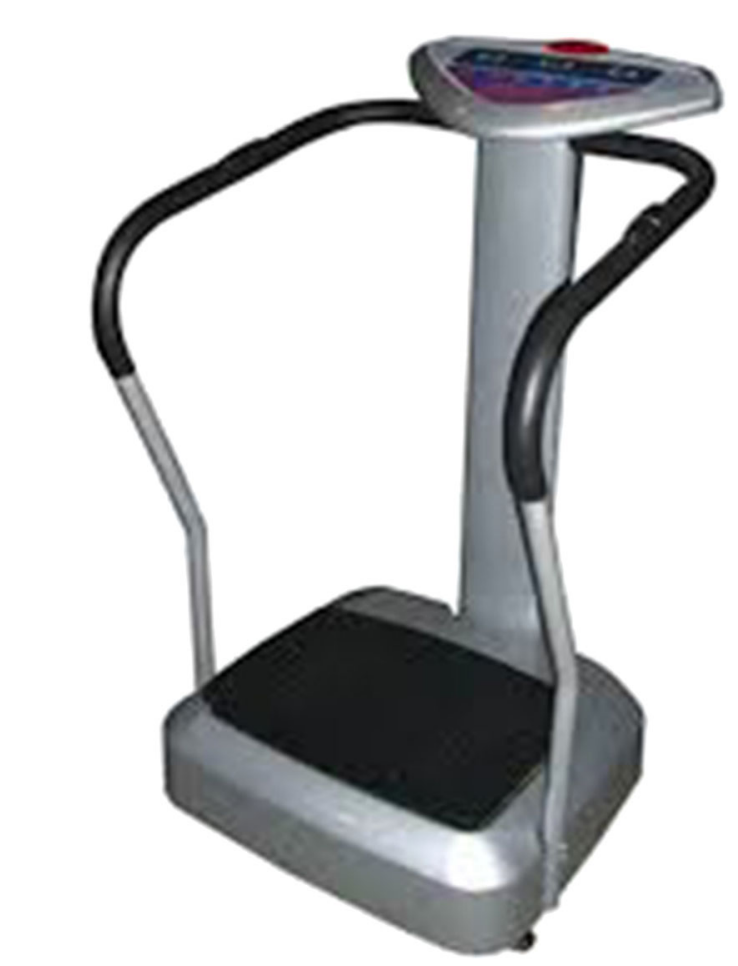

Fig. 3 A representative instrument for the application of whole-body vibration 


\section{WBV in chronic stroke}

In the present section, we review the RCT studies applying WBV in patients with chronic stroke with the aim of promoting post-stroke recovery. The demographic data and clinical features are shown in detail in Table 3. A detailed description of purposes, technical aspects of WBV, outcome measures, timing of follow-up, and finally main results achieved by each of the studies here reviewed are shown in Table 4.

The age of patients recruited in all the previously published WBV studies is generally comparable with a rather balanced proportion of males and females in two studies [55, 59] but not in the other six studies (unbalanced with a majority of males). Although all patients enrolled in the WBV studies have been classified as chronic stroke patients, the exact time interval between stroke and WBV application varied significantly. All the studies enrolled patients at least 6 months following a stroke except for Brogårdhet at al. [54] who did not clarify the time interval from stroke and WBV application. A limitation of the WBV studies concerns the lack of a clear and detailed description of the type (ischemic or hemorrhagic stroke), localization (cortical or subcortical, affected hemisphere), and extension of stroke.

Concerning the specific parameters used during WBV, there was a variety of protocols with frequencies ranging from 5 to $40 \mathrm{~Hz}[55,56,59,61]$ and amplitudes ranging from $0.44 \mathrm{~mm}$ to $6 \mathrm{~mm}$. Ranges of accelerations applied during WBV have been not clarified. The duration of WBV also varied significantly among studies ranging from $30 \mathrm{~s}$ to $2.5 \mathrm{~min}$. Moreover, most of the WBV studies planned repeated sessions of WBV ranging from 17 [59] to 30 [61] with the exception of two studies $[57,58]$ who evaluated the effect of a single WBV session. Liao [61] investigated the effect of lowintensity and high-intensity WBV with respect to sham stimulation.

The outcome variables measured to clarify the possible beneficial effects of WBV included clinical, neurophysiological, and behavioral data. Some authors evaluated the severity of spasticity by means of the Modified Ashworth scale $[56,58]$, others calculated the $\mathrm{H} / \mathrm{M}$ ratio [58], while some measured balance [59] or muscle strength $[54,55,57,60$, 61]. Outcome measures also included serum level of specific collagen proteins [56] or ultrasound evaluation of muscle structure [59]. The effect of WBV on all these clinical, neurophysiological, and behavioral measures is rather inconsistent. Pang [56] found differences in the severity of spasticity, whereas Tankisheva et al. [55] did not. However, a beneficial effect of WBV on muscle strength in patients with chronic stroke was reported by both studies. Chan et al. [58] found a significant reduction of spasticity clinically tested by means of the Modified Ashworth scale and by using the H/M ratio. Other studies, however, did not confirm the effect of WBV on muscle strength in patients with chronic stroke $[54,59,60]$. Studies evaluating balance before and after WBV found no beneficial effect in chronic stroke patients [59]. Similarly, measures of clinical functional evaluation in chronic stroke patients such as the 6 Minute Walking Test [60, 61], Timed Up and Go test [57], and Berg Balance Scale [62] revealed non-significant effects of WBV. Concerning the exact timing of clinical, neurophysiological, or behavioral evaluations before and after WBV, many studies have made the evaluation before and soon after WBV [54, 57-59, 61] or at 1 month [56, 60] and 6 weeks following WBV [55]. A detailed description of

Table 3 Demographic data and clinical features of patients with chronic stroke in studies applying whole body vibration (WBV)

\begin{tabular}{|c|c|c|c|c|c|c|c|}
\hline Study & Group & $N$ & Gender $(\mathrm{M} / \mathrm{F})$ & Age (years) & Duration of disease & Side $(\mathrm{L} / \mathrm{R})$ & Type $(\mathrm{I} / \mathrm{H})$ \\
\hline Brogardh et al. [54] & $\begin{array}{l}\text { EG } \\
\text { CG }\end{array}$ & $\begin{array}{l}16 \\
15\end{array}$ & $\begin{array}{l}13 / 3 \\
12 / 3\end{array}$ & $\begin{array}{l}61.3+8.5 \\
63.9+5.8\end{array}$ & $\begin{array}{l}37.4+31.8 \text { months } \\
33.1+29.2 \text { months }\end{array}$ & $\begin{array}{l}9 / 7 \\
7 / 8\end{array}$ & $\begin{array}{l}14 / 2 \\
13 / 2\end{array}$ \\
\hline Tankisheva et al. [55] & $\begin{array}{l}\mathrm{EG} \\
\mathrm{CG}\end{array}$ & $8^{7}$ & $\begin{array}{l}4 / 3 \\
6 / 2\end{array}$ & $\begin{array}{l}57.4+13 \\
65.3+3.7\end{array}$ & $\begin{array}{l}7.71+8.6 \text { years } \\
5.28+3.6 \text { years }\end{array}$ & $\begin{array}{l}4 / 3 \\
4 / 4\end{array}$ & $\begin{array}{l}6 / 1 \\
5 / 3\end{array}$ \\
\hline Pang et al. [56] & $\begin{array}{l}\text { EG } \\
\text { CG }\end{array}$ & $\begin{array}{l}41 \\
41\end{array}$ & $\begin{array}{l}26 / 15 \\
32 / 9\end{array}$ & $\begin{array}{l}57.3+11.3 \\
57.4+11.1\end{array}$ & $\begin{array}{l}4.6+3.5 \text { years } \\
5.3+4.2 \text { years }\end{array}$ & $\begin{array}{l}20 / 21 \\
14 / 27\end{array}$ & $\begin{array}{l}20 / 21 \\
21 / 20\end{array}$ \\
\hline Silva et al. [57] & $\begin{array}{l}\text { EG } \\
\text { CG }\end{array}$ & $\begin{array}{l}28 \\
10\end{array}$ & $\begin{array}{l}19 / 9 \\
8 / 2\end{array}$ & $\begin{array}{l}60.75+11.8 \\
58.1+8.14\end{array}$ & $\begin{array}{l}40.85+68.76 \text { months } \\
39.6+63.55 \text { months }\end{array}$ & $\begin{array}{l}17 / 11 \\
7 / 3\end{array}$ & $\begin{array}{l}25 / 3 \\
8 / 2\end{array}$ \\
\hline Chan et al. [58] & $\begin{array}{l}\mathrm{EG} \\
\mathrm{CG}\end{array}$ & $\begin{array}{l}15 \\
15\end{array}$ & $\begin{array}{l}10 / 5 \\
11 / 4\end{array}$ & $\begin{array}{l}56.07+11.04 \\
54.93+7.45\end{array}$ & $\begin{array}{l}30.4+25.8 \text { months } \\
38.87+38.22 \text { months }\end{array}$ & $\begin{array}{l}12 / 3 \\
7 / 8\end{array}$ & $\begin{array}{l}10 / 5 \\
5 / 10\end{array}$ \\
\hline Marin et al. [59] & $\begin{array}{l}\text { EG } \\
\text { CG }\end{array}$ & $\begin{array}{l}11 \\
9\end{array}$ & $\begin{array}{l}6 / 5 \\
5 / 4\end{array}$ & $\begin{array}{l}62.3+10.6 \\
64.4+7.6\end{array}$ & $\begin{array}{l}4.3+2 \text { years } \\
4.3+3 \text { years }\end{array}$ & $\begin{array}{l}5 / 6 \\
5 / 4\end{array}$ & $\begin{array}{l}10 / 1 \\
7 / 2\end{array}$ \\
\hline Lau et al. [60] & $\begin{array}{l}\mathrm{EG} \\
\mathrm{CG}\end{array}$ & $\begin{array}{l}41 \\
41\end{array}$ & $\begin{array}{l}26 / 15 \\
32 / 9\end{array}$ & $\begin{array}{l}57.3+11.3 \\
57.4+11.1\end{array}$ & $\begin{array}{l}4.6+3.5 \text { years } \\
5.3+4.2 \text { years }\end{array}$ & $\begin{array}{l}20 / 21 \\
14 / 27\end{array}$ & $\begin{array}{l}20 / 21 \\
21 / 20\end{array}$ \\
\hline Liao et al. [61] & $\begin{array}{l}\text { EG LWBV } \\
\text { EG HWBV } \\
\text { CG }\end{array}$ & $\begin{array}{l}28 \\
28 \\
28\end{array}$ & $\begin{array}{l}20 / 8 \\
18 / 10 \\
24 / 4\end{array}$ & $\begin{array}{l}60.8 \pm 8.3 \\
62.9 \pm 10.2 \\
59.8 \pm 9.1\end{array}$ & $\begin{array}{l}8.5 \pm 5.2 \text { years } \\
8.1 \pm 4.2 \text { years } \\
9.0 \pm 4.6 \text { years }\end{array}$ & $\begin{array}{l}20 / 8 \\
19 / 9 \\
12 / 16\end{array}$ & $\begin{array}{l}12 / 16 \\
12 / 16 \\
11 / 17\end{array}$ \\
\hline
\end{tabular}


Table 4 Characteristics of the cited RCT studies regarding whole body vibration (WBV). $C T s$ C-telopeptide of type I collagen cross-links, $B A P$ bone-specific alkaline phosphatase, MAS Modified Ashworth Scale, $B B S$
Berg Balance scale, VAS visual analogic scale, $T U G$ Timed Up and Go test, 6MWT 6-Minute Walk Test

\begin{tabular}{ll}
\hline $\begin{array}{l}\text { Author } \\
\text { (year) }\end{array}$ & Purpose \\
\hline Pang [56] & $\begin{array}{c}\text { To investigate the } \\
\text { effect of WBV on } \\
\text { bone turnover, leg } \\
\text { muscle strength, } \\
\text { motor function and } \\
\text { spasticity }\end{array}$ \\
& \\
& \\
Tankisheva & $\begin{array}{c}\text { To investigate the } \\
\text { effect of a 6-week }\end{array}$ \\
[55] & $\begin{array}{l}\text { WBV training pro- } \\
\text { gram }\end{array}$
\end{tabular}

Marin et al. To analyze the effects [59] of WBV on lower limb muscle architecture, muscle strength, and balance

Chan et al. To investigate the [58] effect of a single session of WBV training on ankle plantar flexion spasticity and gait performance

Brogardh To evaluate the effects et al. of WBV training

[54]

Liao et al. To investigate the [61] effects of different WBV intensities on body functions/structures

WBV (frequency, amplitude, Outcome measure side of the application, time)

\section{The device that generates vertical WBV. Frequency range $20-30 \mathrm{~Hz}$ and amplitude from 0.60-0.44 mm. Three times per week for 8 weeks (total 24 sections) of training following a specific protocol preceded by $15 \mathrm{~min}$ of warm-up ex- ercises}

Vertical vibration platform, 3 Ashworth scale (score 0-4) times a week for 6 weeks. Progressively increasing the intensity by increasing the frequency ( 35 to $40 \mathrm{~Hz}$ ) or the amplitude (1.7 and $2.5 \mathrm{~mm})$

Sessions 1-12: 5

bounds $\times 30 \mathrm{~s}$

Sessions 13-18: 17 bounds $\times 60 \mathrm{~s}$

Vibration platform with an increase in frequency (from 5 to $21 \mathrm{~Hz}$ ), sets (from 4 to 7), and time per set (from 30 to $60 \mathrm{~s}$ ) during 17 sessions. Amplitude ranged between 4 and $6 \mathrm{~mm}$ peak to peak

A single session of vertical WBV with a magnitude of $12 \mathrm{~Hz}$ and an amplitude of $4 \mathrm{~mm}$

Subjects were positioned on the platform in semi-squat position and the time course included two 10 -min periods of vibration with a 1-min rest interval

\section{applied on the} gastrocnemius, soleus, quadriceps, hamstrings, adductors, and psoas muscles

Knee extension and flexion strength with an isokinetic dynamometer

Sensory organization test for postural control

Ultrasound evaluation of muscle architecture. BBS. Muscle strength

MAS. Subject experience of the influence of ankle spasticity on ambulation was scored by VAS. The maximal amplitude of $\mathrm{H}$ reflex and the

Hmax/Mmax ratio to assess ankle spasticity. The time up and go test. A force plate was used to measure foot pressure

12 sessions of WBV training (twice weekly during 6 weeks) on a vibrating platform

The EG trained on a vibrating platform with an amplitude of $3.75 \mathrm{~mm}$

The CG trained on a vibrating platform with an amplitude of $0.2 \mathrm{~mm}$. The frequency on both platforms was set to $25 \mathrm{~Hz}$

Patients were randomly assigned a low-intensity WBV (frequency $20 \mathrm{~Hz}$ $1 \mathrm{~mm}$ amplitude), high-intensity WBV muscle strength (primary
Isokinetic and isometric knee Pre- and outcome measures), muscle tone, balance, gait performance, and perceived participation (secondary outcome measures) were assessed during $2 \mathrm{~h}$ before and after the WBV training

Knee muscle strength (isokinetic dynamometry), knee and ankle joint spasticity with MAS, balance (Mini Balance post--

Follow-up Results
Baseline, immediately after 24 session program and 1 month after the termination of training
No significant effect on serum levels of CTx and BAP
A significant time effect in the concentric knee flexion power
Significant knee difference in knee MAS score

Baseline, after the No significant differences in intervention the Ashworth scale; a period of significant difference in 6 weeks and after 6 weeks of follow-up isometric knee extension strength

Before and after treatment

Before and after treatment

post-training

No significant differences were found in any outcome measures between the $\mathrm{EG}$ and $\mathrm{CG}$ after 6 weeks

At baseline and intervention
Increased muscle thickness observed in both groups. No statistically significant difference observed in the BBS and in muscle strength

Hmax/Mmax ratio significantly decreased in the EG

Time up and go significantly improved in EG

MAS and VAS showed a significant difference between EG and CG 
Table 4 (continued)

\begin{tabular}{|c|c|c|c|c|c|}
\hline $\begin{array}{l}\text { Author } \\
\text { (year) }\end{array}$ & Purpose & $\begin{array}{l}\text { WBV (frequency, amplitude, } \\
\text { side of the application, time) }\end{array}$ & Outcome measure & Follow-up & Results \\
\hline & $\begin{array}{l}\text { activity, and partici- } \\
\text { pation }\end{array}$ & $\begin{array}{l}\text { (frequency } 30 \mathrm{~Hz}, 1 \mathrm{~mm} \\
\text { amplitude), or CG }\end{array}$ & $\begin{array}{l}\text { Evaluation Systems Test), } \\
\text { mobility (TUG), walking } \\
\text { endurance (6MWT), } \\
\text { balance self-efficacy } \\
\text { (Activities-specific } \\
\text { Balance Confidence } \\
\text { scale), participation in dai- } \\
\text { ly activities (Frenchay } \\
\text { Activity Index), perceived } \\
\text { environmental barriers to } \\
\text { societal participation } \\
\text { (Craig Hospital Inventory } \\
\text { of Environmental Factors), } \\
\text { and quality of life } \\
\text { (Short-Form } 12 \text { Health } \\
\text { Survey) }\end{array}$ & & $\begin{array}{l}\text { Mini Balance Evaluation } \\
\text { Systems Test, the } \\
\text { Activities-specific Balance } \\
\text { Confidence scale, and the } \\
\text { Short-Form } 12 \text { Health } \\
\text { Survey physical composite } \\
\text { score domain }\end{array}$ \\
\hline $\begin{array}{l}\text { Silva et al. } \\
\text { [57] }\end{array}$ & $\begin{array}{l}\text { To investigate the } \\
\text { acute effects of } \\
\text { WBV on motor } \\
\text { function }\end{array}$ & $\begin{array}{l}\text { One session of WBV } \\
\text { (frequency of } 50 \mathrm{~Hz} \text { and } \\
\text { amplitude of } 2 \mathrm{~mm} \text { ) } \\
\text { comprising four 1-min se- } \\
\text { ries with 1-min rest inter- } \\
\text { vals between series in } \\
\text { three body positions: bi- } \\
\text { pedal stances with the } \\
\text { knees flexed to } 30^{\circ} \text { and } \\
90^{\circ} \text { and a unipedal stance } \\
\text { on the paretic limb }\end{array}$ & $\begin{array}{l}\text { Simultaneous } \\
\text { electromyography of the } \\
\text { affected and unaffected } \\
\text { tibialis anterior and rectus } \\
\text { femoris muscles bilaterally } \\
\text { in voluntary isometric } \\
\text { contraction; the 6MWT; } \\
\text { the Stair-Climb Test; and } \\
\text { the TUG }\end{array}$ & $\begin{array}{l}\text { Before and after } \\
\text { vibration } \\
\text { therapy }\end{array}$ & $\begin{array}{l}\text { No effects on the group and } \\
\text { time interaction relative to } \\
\text { variables affected side } \\
\text { rectus femoris, unaffected } \\
\text { side rectus femoris, } \\
\text { affected side tibialis } \\
\text { anterior, unaffected side } \\
\text { tibialis anterior, and the } \\
\text { Stair-Climb Test }\end{array}$ \\
\hline $\begin{array}{l}\text { Lau et al. } \\
\text { [60] }\end{array}$ & $\begin{array}{l}\text { To examine the } \\
\text { efficacy of WBV in } \\
\text { optimizing } \\
\text { neuromotor } \\
\text { performance and } \\
\text { reducing falls }\end{array}$ & $\begin{array}{l}\text { The EG received } 9-15 \text { min of } \\
\text { WBV (vertical vibration; } \\
\text { frequency }=20-30 \mathrm{~Hz} \\
\text { amplitude }=0.44-0.60 \\
\text { mm, peak } \\
\text { acceleration }=9.5-15.8 \text { ) } \\
\text { while performing a variety } \\
\text { of dynamic leg exercises } \\
\text { on the vibration platform. } \\
\text { The CG performed the } \\
\text { same exercises without } \\
\text { vibration. The subjects } \\
\text { underwent their respective } \\
\text { training three times a week } \\
\text { for } 8 \text { weeks }\end{array}$ & $\begin{array}{l}\text { Balance (BBS), mobility } \\
\text { (10-m walk test and } \\
\text { 6MWT), knee muscle } \\
\text { strength (isokinetic } \\
\text { dynamometry), and } \\
\text { fall-related self-efficacy } \\
\text { (activities-specific balance } \\
\text { confidence scale) }\end{array}$ & $\begin{array}{l}\text { At baseline, } \\
\text { immediately } \\
\text { after the } \\
\text { 8-week training } \\
\text { and at 1-month } \\
\text { follow-up }\end{array}$ & $\begin{array}{l}\text { Significant improvement in } \\
\text { balance, mobility, muscle } \\
\text { strength, and fall-related } \\
\text { self-efficacy measures in } \\
\text { both groups after the } \\
\text { 8-week treatment period }\end{array}$ \\
\hline
\end{tabular}

the main results achieved by the WBV studies is shown in Table 4.

\section{Discussion}

Muscle vibration seems to be a safe method possibly helping to improve the outcome of stroke patients. Despite the growing amount of literature in this research field, a relevant number of issues remain still unsolved. First, to analyze the role of a rehabilitative intervention in stroke patients, it should be mainly taken into account that stroke is a heterogeneous condition, thus entailing different degrees of damage with different recovery mechanisms. In this view, there is a lack of RCTs designed to investigate how the potential for stroke recovery and the benefit from rehabilitation strategies vary according to stroke (lesion) characteristics. Indeed, most of the studies that analyzed the effects of $\mathrm{AMV} / \mathrm{WBV}$ on stroke recovery did not report subgroup analysis focused on the different lesion localizations, or yet extent and number of brain lesions. It is known that the global burden and persistence of post-stroke functional deficit crucially reflect infarct size and lesion location (e.g., cortical or subcortical stroke). Patients with cortical stroke are known to manifest worse baseline 
National Institute of Health Scale/Score (i.e., stroke severity) on average than patients with subcortical lesions. Conversely, a single subcortical white matter damage would result in cortical differentiation causing widespread cortical dysfunction or severe motor impairment and poor motor recovery [63, 64]. Hence, when evaluating the effect of fMV/WBV on post-stroke recovery, it should be taken into account that the efficacy would depend on the specific pattern of brain damage [62]. Only a few sporadic case series have been carried out specifically on this issue. A single study from Marconi [15] reported that fMV-induced effects on 31 chronic stroke patients varied depending on whether the stroke was cortical or subcortical. However, further RCTs with larger cohorts of subjects are needed to verify these observations. Beyond cortical and subcortical stroke localization, other clinical features would influence the degree of post-stroke recovery such as stroke severity upon admission [65], hemispheric lateralization, stroke volume, number of lesions and patients' characteristics such as gender and age [66], and presence of aphasia or visual field deficit [66].

A further aspect concerns the optimal timing of intervention. Motor recovery is thought to be almost completed within 10 weeks by stroke occurrence, and stroke recovery reaches a plateau 3 to 6 months after stroke onset [67]; accordingly, most of the post-stroke rehabilitation guidelines suggest to begin the rehabilitation program in the very early phase of acute stroke. Since the very first hours after stroke, the role of changes in perilesional and remote brain regions triggered by the focal brain lesion, and the role of the recruitment of remote or secondary brain structures might play a role in the various degrees of motor recovery $[68,69]$.

Another relevant point concerns the putative physiological mechanisms responsible for the beneficial effect induced by vibration protocols. Several studies in animals and in humans have demonstrated that experimental modulation of proprioceptive inputs to the CNS can re-shape cortical mapping in the sensorimotor region, owing to use-dependent plasticity processes [70-73]. For instance, limb immobilization can deteriorate cortical motor representation of the target body region, reduce cortical excitability, and degrade motor learning [70, 71]. Hence, it might be argued that the fMV/WBV-induced selective stimulation of muscle spindles might elicit changes in afferent sensory inputs to the CNS possibly leading to beneficial cortical/subcortical brain reorganization sensorimotor processes in various neurological conditions imposing limb immobilization such as stroke. It is known that in patients with stroke, the severity of motor deficit reflects two main pathophysiological processes: (1) loss of function due to neuronal loss and (2) maladaptive use-dependent plasticity in survived cortical/subcortical regions operating in both the affected and unaffected hemisphere [74]. Stroke-induced limb immobilization would, therefore, imply reduced afferent inputs to the CNS driving to low activation of cortical/subcortical motor maps coupled with increased inhibition from survived brain regions. As a result, reduced use-dependent cortical plasticity would further deteriorate the motor outcome and delay significantly the timing of post-stroke functional recovery [74]. Hence, we speculate that $\mathrm{MV} / \mathrm{WBV}$ would, in theory, promote post-stroke functional recovery by enhancing proprioceptive inputs to the CNS and inducing beneficial cortical and subcortical reorganization processes based on re-balancing and shaping of cortical and subcortical sensori-motor representations.

A final comment concerns the direct comparison between the amount of after-effects induced by $\mathrm{MMV}$ and WBV, in terms of post-stroke motor recovery. The experimental and clinical data coming from the RCT studies point to the fragility of the WBV after-effects when compared to fMV, in patients with stroke. The inconsistent results observed in previous WBV studies in stroke would reflect a number of methodological reasons including the relevant variability in the stimulating parameters and experimental design used. A possible
Table 5 Recommendation for optimal technical application of focal muscle vibration (fMV) and whole body vibration (WBV)

\begin{tabular}{|c|c|c|}
\hline \multirow[t]{7}{*}{ fMV } & Frequency & $70-120 \mathrm{~Hz}[19,29,46-48,50-54,85]$ \\
\hline & Amplitude & $10 \mu \mathrm{m}-1 \mathrm{~mm}[19,45,47,51-53,59]$ \\
\hline & Target muscle & Upper limb: flexor muscles $[19,45,47,50,51,59]$ \\
\hline & & Lower limb: less clear, preferentially extensor muscles $[52,53]$ \\
\hline & $\begin{array}{l}\text { State of the muscle during the } \\
\text { intervention }\end{array}$ & Mild tonic contraction $[19,45,47,50,52]$ \\
\hline & Duration & $10-30 \min [19,42,45-47,52,53,59]$ \\
\hline & Design & Repetitive sessions $[19,42,45-47,52,53,59]$ \\
\hline \multirow[t]{6}{*}{ WBV } & Frequency & $20-40 \mathrm{~Hz}[57,58,60,62,65]$ \\
\hline & Amplitude & $1-4 \mathrm{~mm}[56-58,60,63,64]$ \\
\hline & Acceleration & Not clear, presumably between 0.3 and $15 \mathrm{~g}$ [62] \\
\hline & $\begin{array}{l}\text { State of the muscle during the } \\
\text { intervention }\end{array}$ & Mild tonic contraction $[56-58,60,62-65]$ \\
\hline & Duration & Variable between maximum $10-15 \min [58,61-65]$ \\
\hline & Design & Repetitive sessions $[56-58,60,65]$ \\
\hline
\end{tabular}


future scenario would also imply different target stroke populations for the two muscle vibration techniques. Repetitive sessions of fMV would be more suitable for neurorehabilitative applications in patients with post-stroke. By contrast, stroke patients manifesting gait and balance impairment would, in theory, benefit from repetitive WBV applications due to the possible beneficial effect of perturbation of the gravitational field [51, 52].

Based on the currently available experimental and clinical data here examined, through this narrative review, we propose a new recommendation for optimal technical application of fMV and WBV in patients with stroke (Table 5). Our recommendation also includes new proposed strategies for the recruitment of specific cohorts of patients with the aim to increase the likelihood for a vibration-induced beneficial symptomatic effect in terms of post-stroke motor recovery. Future studies with fMV/WBV should be designed in patients with cortical rather than subcortical strokes that may imply more severe white matter lesions which in turn preclude motor recovery after stroke [74]. In addition, fMV and WBV should be applied in patients with acute or subacute stroke rather than in chronic stroke thus increasing the likelihood for the occurrence of cortical reorganization processes (cortical plasticity), well-known crucial mechanisms underlying motor recovery after stroke [74]. It should be taken into account that optimal response to muscle vibration would require active target muscle contraction during the intervention (Table 5). Accordingly, future studies should recruit patients with consistent and residual muscle force and exclude those with severe muscle weakness.

In conclusion, we suggest that future studies should be designed in clinically homogeneous cohorts of patients with stroke taking into account our proposed recommendation for optimal technical application of fMV and WBV. Moreover, besides the evaluation of patient's clinical features by means of clinical scales, future studies should also include standardized outcome measures based on more advanced and objective technologies. This study design would finally allow a better comparison between fMV and WBV in terms of symptomatic improvement in patients with stroke.

Funding This research received no external funding.

\section{Compliance with ethical standards}

Conflict of interest The authors declare that they have no conflicts of interest.

Abbreviations BAP, bone-specific alkaline phosphatase; BB, biceps brachii; BBS, Berg Balance Scale; CG, control group; CTs, C-telopeptide of type I collagen cross-links; DALYs, disability-adjusted life-years; EG, experimental group; FAS, Functional Ability Scale; FMA-UE, FuglMeyer Assessment of sensorimotor function after stroke for upper extremity; fMV, focal muscle vibration; FRC, flexor carpi radialis; ICF, intracortical facilitation; JTT, Jebsen-Taylor Hand Function Test; MAS, Modified Ashworth Scale; MEP, motor-evoked potentials; MI, Motricity index; PT, physiotherapy; RMT, resting motor threshold; rMV, repetitive muscle vibration; SICI, short-interval intracortical inhibition; TMS, transcranial magnetic stimulation; TUG, Timed Up and Go test; VAS, visual analogic scale; VNRS, Verbal Numerical Rating Scale of pain; WBV, whole body vibration; 6MWT, 6

Minute Walk Test; WMFT, Wolf Motor Function Test

\section{References}

1. Hankey GJ (2017) Stroke. Lancet 11(389):641-654

2. Kolominsky-Rabas PL, Weber M, Gefeller O, Neundoerfer B, Heuschmann PU (2001) Epidemiology of ischemic stroke subtypes according to TOAST criteria: incidence, recurrence, and long-term survival in ischemic stroke subtypes: a population-based study. Stroke 32(12):2735-2740

3. Feigin VL, Mensah GA, Norrving B, Murray CJ, Roth GA, GBD (2013) Stroke panel experts group (2015) atlas of the global burden of stroke (1990-2013): the GBD 2013 study. Neuroepidemiology 45(3):230-236

4. Langhorne P, Coupar F, Pollock A (2009) Motor recovery after stroke: a systematic review. Lancet Neurol 8(8):741-754

5. O'Dell MW, Lin CC, Harrison V (2009) Stroke rehabilitation: strategies to enhance motor recovery. Annu Rev Med 60:55-68

6. Small SL, Buccino G, Solodkin A (2013) Brain repair after stroke - a novel neurological model. Nat Rev Neurol 9(12):698 707

7. Charcot JM (2011) Vibratory therapeutics. -the application of rapid and continuous vibrations to the treatment of certain diseases of the nervous system. 1892. J Nerv Ment Dis 199(11):821-827

8. Goetz CG (2009) Jean-Martin Charcot and his vibratory chair for Parkinson disease. Neurology 73(6):475-478

9. Hagbarth KE, Eklund G (1968) The effects of muscle vibration in spasticity, rigidity, and cerebellar disorders. J Neurol Neurosurg Psychiatry 31(3):207-213

10. Bishop B (1975) Vibratory stimulation Part III Possible applications of vibration in treatment of motor dysfunctions. Phys Ther 55(2): 139-143

11. Ward NS, Cohen LG (2004) Mechanism underlying recovery of motor function after stroke. Arch Neurol 61(12):1844-1848

12. Christova M, Rafolt D, Mayr W, Wilfling B, Gallasch E (2010) Vibration stimulation during non-fatiguing tonic contraction induces outlasting neuroplastic effects. J Electromyogr Kinesiol 20(4):627-635

13. Forner-Cordero A, Steyvers M, Levin O, Alaerts K, Swinnen SP (2008) Changes in corticomotor excitability following prolonged muscle tendon vibration. Behav Brain Res 190(1):41-49

14. Marconi B, Filippi GM, Koch G, Pecchioli C, Salerno S, Don R, Camerota F, Saraceni VM, Caltagirone C (2008) Long-term effects on motor cortical excitability induced by repeated muscle vibration during contraction in healthy subjects. J Neurol Sci 275(1-2):51-59

15. Marconi B, Filippi GM, Koch G, Giacobbe V, Pecchioli C, Versace V, Camerota F, Saraceni VM, Caltagirone (2011) Long-term effects on cortical excitability and motor recovery induced by repeated muscle vibration in chronic stroke patients. Neurorehabil Neural Repair 25(1):48-60

16. Mileva KN, Bowtell JL, Kossev AR (2009) Effects of lowfrequency whole-body vibration on motor-evoked potentials in healthy men. Exp Physiol 94(1):103-116

17. Pettorossi VE, Schieppati M (2014) Neck proprioception shapes body orientation and perception of motion. Front Hum Neurosci 8:895 
18. Pettorossi VE, Panichi R, Botti FM, Biscarini A, Filippi GM, Schieppati M (2015) Long-lasting effects of neck muscle vibration and contraction on self-motion perception of vestibular origin. Clin Neurophysiol 126(10):1886-1900

19. Rosenkranz K, Rothwell JC (2003) Differential effect of muscle vibration on intracortical inhibitory circuits in humans. J Physiol 551(Pt 2):649-660

20. Swayne O, Rothwell J, Rosenkranz K (2006) Transcallosal sensorimotor integration: effects of sensory input on cortical projections to the contralateral hand. Clin Neurophysiol 117(4):855-863

21. Lu J, Xu G, Wang Y (2015) Effects of whole body vibration training on people with chronic stroke: a systematic review and metaanalysis. Top Stroke Rehabil 22(3):161-168

22. La Torre G, Backhaus I, Mannocci A (2015) Rating for narrative reviews: concept and development of the International Narrative Systematic Assessment tool. Senses Sci 2:31-35

23. Hunt CC (1961) On the nature of vibration receptors in the hind limb of the cat. J Physiol 155:175-186

24. Ribot-Ciscar E, Roll JP, Tardy-Gervet MF, Harlay F (1996) Alteration of human cutaneous afferent discharges as the result of long-lasting vibration. J Appl Physiol 80(5):1708-1715

25. Roll JP, Vedel JP (1982) Kinaesthetic role of muscle afferents in man, studied by tendon vibration and microneurography. Exp Brain Res 47(2):177-190

26. Burke D, Hagbarth KE, Löfstedt L, Wallin BG (1976) The responses of human muscle spindle endings to vibration of noncontracting muscles. J Physiol 261(3):673-693

27. Burke D, McKeon B, Westerman RA (1980) Induced changes in the thresholds for voluntary activation of human spindle endings. J Physiol 302:171-181

28. Hayward LF, Nielsen RP, Heckman CJ, Hutton RS (1986) Tendon vibration-induced inhibition of human and cat triceps surae group I reflexes: evidence of selective Ib afferent fiber activation. Exp Neurol 94:333-347

29. Brown MC, Engberg I, Matthews PB (1967) The relative sensitivity to vibration of muscle receptors of the cat. J Physiol 92:773-800

30. Roll JP, Vedel JP, Ribot E (1989) Alteration of proprioceptive messages induced by tendon vibration in man: a microneurographic study. Exp Brain Res 76:213-222

31. Souron R, Besson T, Millet GY, Lapole T (2017) Acute and chronic neuromuscular adaptations to local vibration training. Eur J Appl Physiol 117:1939-1964

32. Fallon JB, Macefield VG (2007) Vibration sensitivity of human muscle spindles and Golgi tendon organs. Muscle Nerve 36:21-29

33. Rosenkranz K, Rothwell JC (2004) The effect of sensory input and attention on the sensorimotor organization of the hand area of the human motor cortex. J Physiol 561:307-320

34. Hagbarth KE, Wallin G, Löfstedt L (1973) Muscle spindle responses to stretch in normal and spastic subjects. Scand J Rehabil Med 5:156-159

35. Eklund G, Hagbarth KE (1966) Normal variability of tonic vibration reflexes in man. Exp Neurol 16:80-92

36. Nordin M, Hagbarth KE (1996) Effects of preceding movements and contractions on the tonic vibration reflex of human finger extensor muscles. Acta Physiol Scand 156:435-440

37. De Domenico G (1979) Tonic vibratory reflex. What is it? Can we use it? Physiotherapy 65:44-48

38. Matthews PB (1966) The reflex excitation of the soleus muscle of the decerebrate cat caused by vibration applied to its tendon. J Physiol 184:450-472

39. Vallbo AB (1970) Response patterns of human muscle spindle endings to isometric voluntary contractions. Acta Physiol Scand 80: $43 \mathrm{~A}$

40. Hagbarth KE, Eklund G (1966) Tonic vibration reflexes (TVR) in spasticity. Brain Res 2:201-203
41. Murillo N, Valls-Sole J, Vidal J, Opisso E, Medina J, Kumru H (2014) Focal vibration in neurorehabilitation. Eur J Phys Rehabil Med 50:231-242

42. Paoloni M, Mangone M, Scettri P, Procaccianti R, Cometa A, Santilli V (2010) Segmental muscle vibration improves walking in chronic stroke patients with foot drop: a randomized controlled trial. Neurorehabil Neural Repair 24:254-262

43. Conrad MO, Scheidt RA, Schmit BD (2011) Effects of wrist tendon vibration on arm tracking in people poststroke. J Neurophysiol 106: $1480-1488$

44. Caliandro P, Celletti C, Padua L, Minciotti I, Russo G, Granata G, La Torre G, Granieri E, Camerota F (2012) Focal muscle vibration in the treatment of upper limb spasticity: a pilot randomized controlled trial in patients with chronic stroke. Arch Phys Med Rehabil 93:1656-1661

45. Noma T, Matsumoto S, Shimodozono M, Etoh S, Kawahira K (2012) Anti-spastic effects of the direct application of vibratory stimuli to the spastic muscles of hemiplegic limbs in post-stroke patients: a proof-of-principle study. J Rehabil Med 44:325-330

46. Lee SW, Cho KH, Lee WH (2013) Effect of a local vibration stimulus training programme on postural sway and gait in chronic stroke patients: a randomized controlled trial. Clin Rehabil 27:921-931

47. Tavernese E, Paoloni M, Mangone M, Mandic V, Sale P, Franceschini M, Santili V (2013) Segmental muscle vibration improves reaching movement in patients with chronic stroke A randomized controlled trial. NeuroRehabilitation 32:591-599

48. Casale R, Damiani C, Maestri R, Fundarò C, Chimento P, Foti C (2014) Localized $100 \mathrm{~Hz}$ vibration improves function and reduces upper limb spasticity: a double-blind controlled study. Eur J Phys Rehabil Med 50:495-504

49. Costantino C, Galuppo L, Romiti D (2017) Short-term effect of local muscle vibration treatment versus sham therapy on upper limb in chronic post-stroke patients: a randomized controlled trial. Eur J Phys Rehabil Med 53:32-40

50. Celletti C, Sinibaldi E, Pierelli F, Monari G, Camerota F (2017) Focal muscle vibration and progressive modular rebalancing with neurokinetic facilitations in post-stroke recovery of upper limb. Clin Ter 168:e33-e36

51. Cardinale M, Bosco C (2003) The use of vibration as an exercise intervention. Exerc Sport Sci Rev 31:3-7

52. Muir J, Kiel DP, Rubin CT (2013) Safety and severity of accelerations delivered from whole body vibration exercise devices to standing adults. J Sci Med Sport 16:526-531

53. Abercromby AF, Amonette WE, Layne CS, McFarlin BK, Hinman MR, Paloski WH (2007) Vibration exposure and biodynamic responses during whole-body vibration training. Med Sci Sports Exerc 39:1794-1800

54. Brogårdh C, Flansbjer UB, Lexell J (2012) No specific effect of whole-body vibration training in chronic stroke: a double-blind randomized controlled study. Arch Phys Med Rehabil 93:253-258

55. Tankisheva E, Bogaerts A, Boonen S, Feys H, Verschueren S (2014) Effects of intensive whole-body vibration training on muscle strength and balance in adults with chronic stroke: a randomized controlled pilot study. Arch Phys Med Rehabil 95:439-446

56. Pang MY, Lau RW, Yip SP (2013) The effects of whole-body vibration therapy on bone turnover, muscle strength, motor function, and spasticity in chronic stroke: a randomized controlled trial. Eur J Phys Rehabil Med 49:439-450

57. Silva AT, Dias MP, Calixto R Jr, Carone AL, Martinez BB, Silva AM, Honorato DC (2014) Acute effects of whole-body vibration on the motor function of patients with stroke: a randomized clinical trial. Am J Phys Med Rehabil 93:310-319

58. Chan KS, Liu CW, Chen TW, Weng MC, Huang MH, Chen $\mathrm{CH}$ (2012) Effects of a single session of whole-body vibration on ankle plantarflexion spasticity and gait performance in patients with 
chronic stroke: a randomized controlled trial. Clin Rehabil 26: 1087-1095

59. Marín PJ, Ferrero CM, Menéndez H, Martín J, Herrero AJ (2013) Effects of whole-body vibration on muscle architecture, muscle strength, and balance in stroke patients: a randomized controlled trial. Am J Phys Med Rehabil 92:881-888

60. Lau RW, Yip SP, Pang MY (2012) Whole-body vibration has no effect on neuromotor function and falls in chronic stroke. Med Sci Sports Exerc 44:1409-1418

61. Liao RN, Ng GY, Jones AY, Huang MZ, Pang MY (2016) Wholebody vibration intensities in chronic stroke: a randomized controlled trial. Med Sci Sports Exerc 48:1227-1238

62. Boychuk JA, Schwerin SC, Thomas N, Roger A, Silvera G, Liverpool M, Adkins DL, Kleim JA (2016) Enhanced motor recovery after stroke with combined cortical stimulation and rehabilitative training is dependent on infarct location. Neurorehabil Neural Repair 30:173-181

63. Liu G, Tan S, Dang C, Peng K, Xie C, Xing S, Zeng J (2017) Motor recovery prediction with clinical assessment and local diffusion homogeneity after acute subcortical infarction. Stroke 48:21212128

64. Puig J, Pedraza S, Blasco G, Daunis-I-Estadella J, Prados F, Remollo S, Prats-Galino A, Soria G, Boada I, Castellanos M et al (2011) Acute damage to the posterior limb of the internal capsule on diffusion tensor tractography as an early imaging predictor of motor outcome after stroke. AJNR Am J Neuroradiol 32:857-863

65. Glymour MM, Berkman LF, Ertel KA, Fay ME, Glass TA, Furie KL (2007) Lesion characteristics, NIH stroke scale, and functional recovery after stroke. Am J Phys Med Rehabil 86:725-733

66. Ntaios G, Faouzi M, Ferrari J, Lang W, Vemmos K, Michel P (2012) An integer-based score to predict functional outcome in acute ischemic stroke. Neurology 78:1916-1922
67. Kwakkel G, Kollen BJ (2013) Predicting activities after stroke: what is clinically relevant? Int J Stroke 8:25-32

68. Grefkes C, Fink GR (2011) Reorganization of cerebral networks after stroke: new insights from neuroimaging with connectivity approaches. Brain 134(Pt 5):1264-1276

69. Talelli P, Greenwood RJ, Rothwell JC (2006) Arm function after stroke: neurophysiological correlates and recovery mechanisms assessed by transcranial magnetic stimulation. Clin Neurophysiol 117(8):1641-1659

70. Hamdy S, Rothwell JC, Aziz Q, Singh KD, Thompson DG (1998) Long-term reorganization of human motor cortex driven by shortterm sensory stimulation. Nat Neurosci 1(1):64-68

71. Milliken GW, Plautz EJ, Nudo RJ (2013) Distal forelimb representations in primary motor cortex are redistributed after forelimb restriction: a longitudinal study in adult squirrel monkeys. J Neurophysiol 109(5):1268-1282

72. Rocchi L, Suppa A, Leodori G, Celletti C, Camerota F, Rothwell J, Berardelli A (2018) Plasticity induced in the human spinal cord by focal muscle vibration. Front Neurol 2(9):935

73. Ca merota F, Celletti C, Suppa A, Galli M, Cimolin V, Filippi GM, La Torre G, Albertini G, Stocchi F, De Pandis MF (2016) Focal muscle vibration improves gait in Parkinson's disease: a pilot randomized, controlled trial. Mov Disord Clin Pract 3(6):559-566

74. Di Pino G, Pellegrino G, Assenza G, Capone F, Ferreri F, Formica D, Ranieri F, Tombini M, Ziemann U, Rothwell JC, Di Lazzaro V (2014) Modulation of brain plasticity in stroke: a novel model for neurorehabilitation. Nat Rev Neurol 10(10):597-608

Publisher's note Springer Nature remains neutral with regard to jurisdictional claims in published maps and institutional affiliations. 